\title{
Museu de arte moderna: a questão da qualidade de serviços
}

\section{Museum of modern art and the quality of service}

\author{
Marcelo Calderari Miguel ${ }^{1}$ Ana Claudia Borges Campos ${ }^{2}$ Sandra Maria Souza de Carvalho \\ ${ }^{1}$ ORCID: https://orcid.org/0000-0002-7876-9392 \\ 2 Universidade Federal de Uberlândia: Uberlândia, Minas Gerais, Brasil. ORCID: https://orcid.org/0000-0002-2820-6938
}

Autor para correspondência/Mail to: Marcelo Calderari Miguel, marcelocalderari@yahoo.com.br

Copyright (C) 2018 Miguel, Campos \& Carvalho. Todo o conteúdo da Revista (incluindo-se instruções, política editorial e modelos) está sob uma licença Creative Commons Atribuição-NãoComercial-Compartilhalgual 3.0 Não Adaptada. Ao serem publicados por esta Revista, os artigos são de livre uso em ambientes educacionais, de pesquisa e não comerciais, com atribuição de autoria obrigatória. Mais informações em http://revistas.ufpr.br/atoz/about/submissions\#copyrightNotice.

\begin{abstract}
Resumo
Introdução: o trabalho apresenta as percepções e expectativas dos visitantes sobre os serviços ofertados no Museu de Arte Murilo Mendes (MAMM) da Universidade Federal de Juiz de Fora.

Objetivos: : trata-se de um estudo exploratório, descritivo, de abordagem quantitativa, visando diagnosticar as dimensões da qualidade: confiabilidade, empatia, garantia, receptividade e tangibilidade.

Metodologia: a técnica adotada foi a métrica Servqual, com levantamento de dados por survey.

Resultados: os resultados indicam a validade e consistência da abordagem, evidência que os respondentes salientam positivamente a dimensão tangibilidade e apontando um grau relativamente baixo de insatisfação em relação às outras quatro determinantes da qualidade em serviços. Conclusão: conclui-se que a escala Servqual é apropriada para apurar a qualidade em espaços de educação não formal e, notadamente, na esfera museológica viabilizar melhoria nas práticas e processo de desenvolvimento de serviços.
\end{abstract}

Palavras-chave: Avaliação de serviços; Gestão de unidades de informação; Modelo de avaliação; Práticas museais; Servqual.

\begin{abstract}
Introduction: this work presents the perceptions and expectations of the visitors about the services offered at the Murilo Mendes Art Museum (MAMM) of the Universidade Federal de Juiz de Fora, State of Minas Gerais, Brazil.

Objectives: this is an exploratory, descriptive, quantitative approach, aiming to diagnose the dimensions of quality: Reliability, Empathy, Assurance, Responsiveness and Tangibility.

Methodology: The technique adopted was the Servqual metric, with data collection by survey.

Results: the results indicate the validity and consistency of the approach, evidence that the respondents positively emphasize the tangibility dimension and pointing out a relatively low degree of dissatisfaction with the other four determinants of quality in services.

Conclusions: it is concluded that the Servqual scale is appropriate to ascertain the quality in spaces of non-formal education and, especially, in the museum sphere, to enable improvement in the practices and process of service developmen.
\end{abstract}

Keywords: Evaluation Model; Management of information units; Practical museums; Service evaluation; Servqual.

\section{INTRODUÇÃO}

Segundo o Instituto Brasileiro de Museus - IBRAM (2018, p. 1), "A museologia é hoje compartilhada como uma prática a serviço da vida". A entidade aponta que o espaço museológico além de fascinante é o lócus de descobertas e aprendizado, ambiência que expande o conhecimento e aprofunda a consciência da identidade, da partilha e da solidariedade. Em suma, o IBRAM conclui que o museu é lugar que conecta sensações, ideias e imagens em prol da iluminação dos valores essenciais para o ser humano.

Cunha $(2018$, p. 3) alerta que "precisamos investir e proteger nossos museus e acervos para o benefício da ciência e da sociedade em todo o mundo. Portanto, basta cumprir os preceitos constitucionais para que os museus possam ser protegidos, preservados e difundidos". Resgatando os princípios encontrados na Constituição Brasileira (Carta Magna) o autor assinala que o patrimônio cultural brasileiro (os bens de natureza material e imaterial) são portadores referenciais da ação, identidade e memória da nossa sociedade.

Gomes e Cazelli (2016, p. 4) reportam que o museu se constitui como "um meio que propicia uma aproximação entre a sociedade e seu patrimônio cultural". O museu é "prática a serviço da vida". Mas como se pensa a qualidade dos serviços institucionais? Como os visitantes veem a organização?

Apesar dos espaços de memória cultural vivenciar constantes ameaças, é pertinente assinalar que a Declaração Universal dos Direitos Humanos, que completou 70 anos, inspirou e move a redação de diversos textos políticos legais pelo mundo e contempla também as áreas de informação no âmbito da Ciência da Informação e nos campos da Biblioteconomia, Arquivologia e Museologia. Diante dos argumentos apresentados e a política de austeridade fiscal (cortes e contingenciamentos no orçamento 2017-2018; abordagem neoliberal das políticas públicas) registra-se hodiernamente que diversas entidades explanam repúdio ao insipiente apoio governamental à ciência, educação, tecnologia, cultura, lazer e desportos no país. 
O objeto da pesquisa é o Museu de Arte Murilo Mendes (MAMM), vinculado a Universidade Federal de Juiz de Fora (UFJF), apresentando o olhar da comunidade de usuários dos seus serviços. A instituição que conquistou 13 anos de existência em junho, 2018 o possui o selo de 'museu registrado', tornando-se um dos 31 museus mineiros (dos 172 brasileiros) com essa certificação (UFJF, 2018, p. 1).

O Registro de Museus é um instrumento da Política Nacional de Museus previsto pelo Estatuto de Museus (Lei 11.904/2009) e regulamentado pelo Decreto $\mathrm{n}^{\circ}$ 8.124/2013 e Resolução Normativa $\mathrm{n}^{\circ}$ $1 / 2016$, e visa criar mecanismos de coleta, análise e compartilhamento de informações sobre os museus brasileiros, com o propósito de aprimorar a qualidade de suas gestões e fortalecer as políticas públicas setoriais. Também intenciona estimular a formalização dos museus a partir do acompanhamento das dinâmicas de criação, fusão, incorporação, cisão ou extinção de museus (IBRAM, 2018, p. 1).

Assim este estudo foi desenvolvido no agitar desse panorama e traz como problemática múltiplos olhares sobre o construto da qualidade através da seguinte questão: como os visitantes de espaços não formais de educação avaliam a qualidade da prestação de serviços que neles ocorre?

Especificamente, o objetivo dessa pesquisa é avaliar a qualidade dos serviços prestados pelo MAMM, segundo a expectativa e a percepção de seus usuários por meio da adaptação da métrica Servqual. O estudo visa identificar a percepção dos visitantes, analisando as determinantes da qualidade como apoio da abordagem teórico-metodológica Servqual, elencado cinco determinantes da qualidade, ou seja, as dimensões tangibilidade, confiabilidade, receptividade, garantia e empatia.

A escala Servqual averigua as lacunas na qualidade de serviços e foi idealizada pelos pesquisadores Parasuraman, Zeithaml e Berry (1985). A escolha da abordagem métrica Servqual deve-se aos relatos satisfatórios de diversos pesquisadores - Rebello (2004); Dlačić e colaboradores (2014); Soares \& Sousa (2015); Miguel (2017); Carvalho, Miguel \& Campos (2007) - validam desse instrumento em estudos organizacionais, bem como a flexibilidade e adaptabilidade da escala Servqual a avaliar um amplo rol de serviços.

A denominação Servqual sucede da junção dos prefixos "serv", de serviços, e de "qual", qualidade. É um diagnóstico baseado em cinco construtos da qualidade e o posterior exame dos hiatos na condução dos serviços (Service Quality Gap Analysis). Trata-se de um norteador para aferir e captar o que se espera (deseja) de um serviço e o que se encontra em um serviço (real desempenho). Este trabalho encontra relevância e justificativa no âmbito da temática da qualidade institucional de espaços não formais de educação.

Ao dirigir a avaliação a partir do olhar dos visitantes e a qualidade percebida dos serviços do MAMM, tangenciamos algumas motivações, tais como: a) acadêmica, que expressa ampliar o entendimento sobre a qualidade de serviços prestados na área museológica da Zona da Mata Mineira; b) científica, que visa contribuir como uma fonte de conhecimento sobre a qualidade e o processo de aprimoramento de espaços não formais e informais de aprendizagem; c) institucional, quando o mapeamento das expectativas e das percepções da comunidade visitante permitirá situar a política de atendimento; e a esfera d) social, pois os resultados angariados poderão reunir subsídios para melhorias e tomada de decisão com base nos anseios da comunidade abordada.

Esse 'durar na zona limite da memória' - olhar poético e muriliano - soa harmônico com a nova corrente museológica, e conforme veremos a seguir, buscaram refletir sobre alguns desses limites, propondo desvincular, por exemplo, os museus da relação com o tempo, tarefa essa difícil para os museus de arte em geral, haja vista suas profundas ligações com a história da arte e sua cronologia.

\section{SÓ NÃO EXISTE O QUE NÃO PODE SER IMAGINADO}

O termo 'museu' vem do latim "museum"que por vez originou-se da palavra grega "Mouseion"- designando o templo das musas (Gaspar, 1993). Relatos históricos contam que Ptolomeu I Sóter (366 - 283 a.C) atribuiu esse nome a uma sala do palácio em Alexandria, local em que se reuniam notáveis sábios e filósofos - assim, esse foi o primeiro estabelecimento cultural que recebeu o título de Museu.

O International Council of Museums (ICOM) - Conselho Internacional de Museus - traz a explicação de que museu compreende toda instituição permanente, sem fins lucrativos, aberta ao público, que adquire, conserva pesquisa e expõe coleções de objetos de caráter cultural ou científico, para fins de estudo, educação e entretenimento. Hallal e Muller (2016, p. 209) alegam que:

Atualmente os museus não são somente espaços em que se guarda, conserva, expõe e comunica memórias, mas também instigam, despertam interesse e relativizam lembranças de forma a gerar novos questionamentos, proposições e representações a seus visitantes. Tornando o indivíduo parte integrante daquele espaço, fazendo com que o morador da localidade vivencie, através da educação patrimonial, a experiência do estranhamento e realize o turismo cidadão.

Bourdieu e Darbel (2007, p. 119) reconhecem que a recepção (dos museus e das obras de arte) depende de esquemas de percepção, de pensamento e de apreciação dos receptores, bem como aponta que há uma conexão 
entre a natureza e a qualidade das informações fornecidas e estrutura do público. Não obstante, os autores apontam que a arte moderna se afirma como uma arte de criação, rompendo com a unidade e instituindo uma pluralidade de visões.

Já Gosling et al. (2016, p. 166) reportam que "visitantes buscam uma experiência total, incluindo lazer, cultura, educação e interação social". Destarte, as experiências dos visitantes torna-se um conceito chave no marketing de patrimônios artísticos e culturais, uma vez que também a satisfação dos visitantes é muitas vezes determinada pela experiência global obtida.

O verso poético de Murilo Mendes anuncia que "só não existe o que não pode ser imaginado"(1994, p. 142). Diante essa passagem, apreendemos que o museu existe para dar ênfase do que pode ser imaginado ou pensado, ganha a consistência de realidade. Ao postularem o museu como uma instituição permanente, mas axiomaticamente é adjacente a uma série de artefatos atinentes a vida cultural, o lazer, a instrução, a fruição a artes, a participação social, o progresso científico apontado juntamente com a discussão da paz social, focaliza a qualidade dos serviços à luz do livre e pleno desenvolvimento da cidadania.

\section{'Tudo vive em transformação'}

O escopo do Museu de Arte Murilo Mendes (MAMM) da Universidade Federal de Juiz de Fora (UFJF, 2018) - inserida no tríplice conceito de ensino, pesquisa e extensão da UFJF - acompanha a necessidade institucionalmente constituída de ser excelência nos campos de literatura, artes visuais e memória. O Museu tem um acervo bibliográfico, documental e de artes plásticas, - considerado o maior ingresso de arte internacional no país. A finalidade dessa instituição é criar a possibilidade de despertar a população para a leitura crítica da modernidade, contribuindo para a perpetuação e a construção da memória social e a valorização de Bens Culturais Musealizados.

O MAMM foi constituído em dezembro de 2005 para abrigar a coleção de artes visuais e o acervo bibliográfico do poeta juiz-forano Murilo Mendes (1901-1975). Essa coleção foi adquirida da família de Mendes para a UFJF pelo governo brasileiro em 1994 conduzido pelo presidente Itamar Franco. O MAMM está instalado na edificação inaugurada em 1966 onde funcionou, ao longo de trinta e nove anos (até 2005), a reitoria da UFJF, transformando assim um espaço administrativo em um local de arte. O prédio foi projetado pelo arquiteto Décio Bracher, com ampla fachada de vidro e linhas modernas que o tornam referência da arquitetura dos anos 60 (UFJF, 2014, p. $1)$.

A origem do MAMM remete a 1976, quando, após o falecimento do poeta no verão de 1975, em Lisboa, sua viúva Maria da Saudade Cortesão Mendes doou sua biblioteca com 2.864 exemplares à universidade, que a abrigou no Centro de Divisão do Conhecimento até 1994, ano de celebração do termo de contrato de transferência para a universidade do acervo de artes visuais de Murilo, integrado por obras de artistas nacionais e estrangeiros. O desenvolvimento de estudos e ações científico-culturais acerca do ensino, pesquisa e extensão constitui a missão do MAMM, norteada nos princípios de preservação, conservação e divulgação dos acervos bibliográficos, documentais e de artes visuais alocados na instituição; de promoção do intercâmbio entre instituições congêneres no âmbito de sua missão; de publicações resultantes de pesquisas e projetos culturais; de incentivo às ações no campo da literatura e artes visuais; e de estabelecimento de políticas de valorização da memória literária juiz-forana (BRASIL, 2015, p. 1).

O MAMM - vinculado à Pró-reitoria de Cultura, criada, em 2006, para o estabelecimento da política cultural no âmbito da UFJF - tem localização privilegiada no centro do município de Juiz de Fora numa área constituída de aproximadamente $2.200 \mathrm{~m}^{2}$, utiliza-se do princípio da planta livre, valorizando os elementos estruturais da obra, com vastos ambientes demarcados por iluminação natural que harmoniza o espaço interno com o espaço externo do museu, definido por amplo jardim e elementos de estilo próprios da arquitetura da época de sua inauguração (1966). (UFJF, 2014, 2018; MAMM, 2015).

O Regimento Interno do MAMM conclama a vocação comprometida com programas, projetos e ações institucionais prioritariamente vinculados à vida e à obra do poeta Murilo Mendes. Assim sendo, o teor do Regimento Interno do museu não cede lugar ao entendimento de organização como um mero centro cultural no qual poderiam ser desenvolvidas atividades diversas e que, portanto, estariam destoantes da missão institucional nele contida. Assim, os preceitos do MAMM num viés interdisciplinar propõe-se a preservação, pesquisa e difusão da vida e obra de Murilo Mendes - poeta protagonista do século XX - bem como de outros temas correlatos. O quadro a seguir destaca a missão, visão e alguns objetivos organizacionais, vejamos:

A coleção de artes visuais, por sua importância no cenário nacional tem um público expressivo de visitantes nas exposições. Já o acervo bibliográfico e documental, por possuir caráter de especificidade, é referência para pesquisadores que estudam a obra de Murilo Mendes. Ainda assim, todo o acervo do museu oferece possibilidades de investigação científica, sendo incipiente o feedback dos pesquisadores e o número de pesquisas realizadas no espaço do MAMM. 


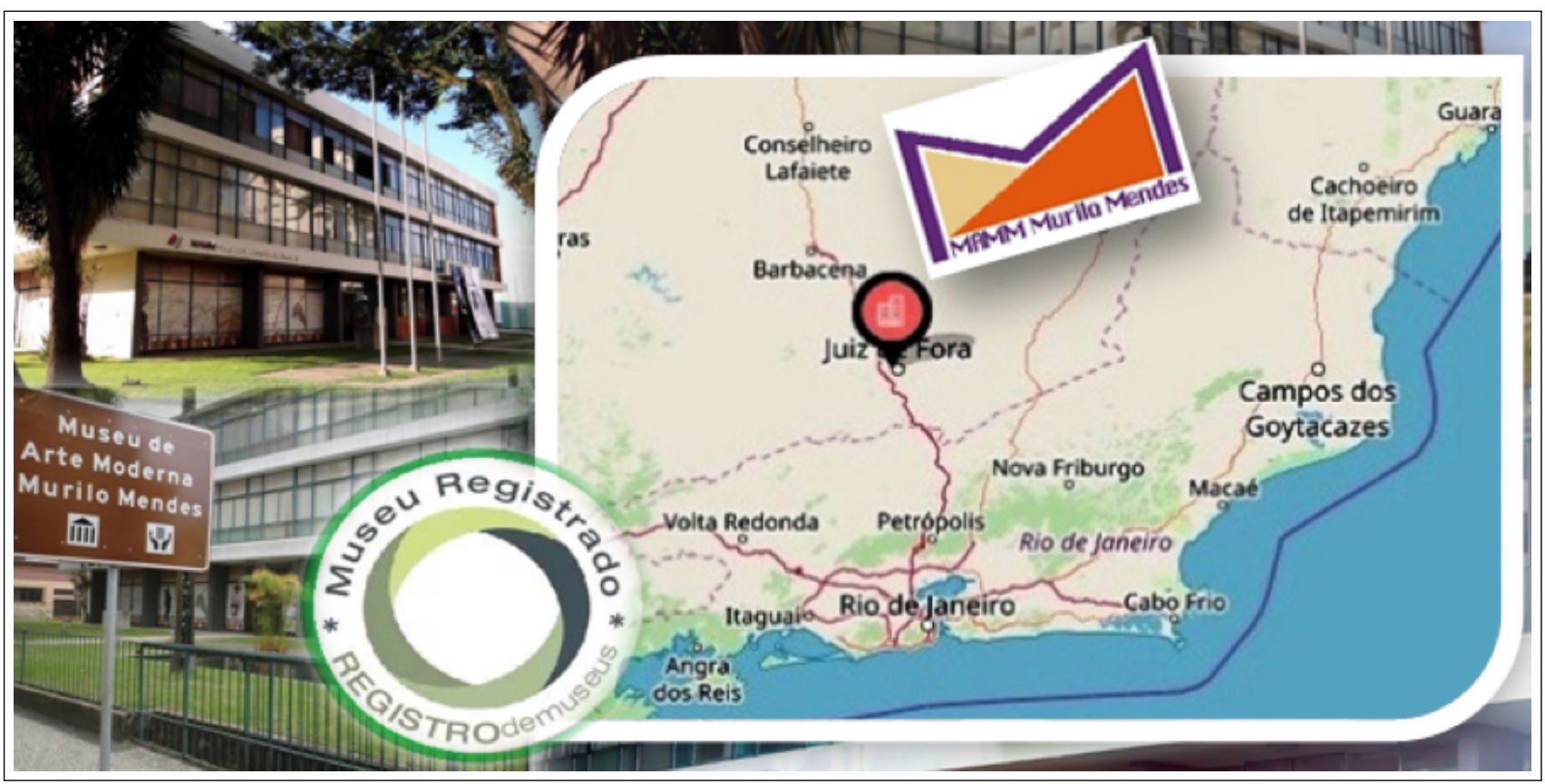

Figura 1. MAMM localização geográfica e característica externa da edificação Fonte: os autores, com base em 'Museusbr' (BRASIL, 2015)

\begin{tabular}{|l|l|}
\hline \multicolumn{2}{|c|}{ Alinhamento organizacional do MAMM } \\
\hline Missão & $\begin{array}{l}\text { Ampliar o acesso da sociedade ao acervo de artes visuais e literário relacionado ao poeta } \\
\text { Murilo Mendes, estimulando e desenvolvendo pesquisas e atividades científico-culturais } \\
\text { para preservar e difundir o pensamento muriliano. }\end{array}$ \\
\hline Visão & $\begin{array}{l}\text { Ser uma instituição museológica de excelência no âmbito da literatura, artes visuais e } \\
\text { memória local e regional com foco em pesquisas e estudos sistemáticos sobre a natureza } \\
\text { e a obra do poeta Murilo Mendes. - sendo este contemporâneo - em consonância com a } \\
\text { missão da UFJF. }\end{array}$ \\
\hline Alguns Objetivos & $\begin{array}{l}\text { Preservar, pesquisar e divulgar os acervos: bibliográfico, arquivístico e museológico que } \\
\text { constituem os estoques informacionais; Promover ações culturais prioritariamente no } \\
\text { âmbito da literatura e das artes visuais. }\end{array}$ \\
\hline
\end{tabular}

Quadro 1. Identidade organizacional do MAMM

Fonte: os autores com base em (UFJF, 2014, 2018; MAMM, 2015).

O acervo do MAMM não se constitui somente pela coleção particular de Murilo Mendes, mas também pela aquisição de obras de artistas que conviveram com Murilo Mendes ou foram contemplados em sua produção literária. No entanto, há no acervo uma coleção peculiar que não se orientou por essa política de aquisição, formada por gravuras realizadas durante a ECO-92 - Congresso internacional promovido pela Organização das Nações Unidas. Nessa coleção encontram-se obras de Arcângelo Ianelli, Beatriz Milhazes, Carlos Vergara, Fernando de Szyszlo, Flávio Shiró, Jorge Tacla, Miguel Angel Rojas, Siron Franco e Tomie Ohtake, entre outros. Essas serigrafias foram distribuídas a instituições de arte e cultura do Brasil pelo Banco Bozano, Simonsen, em 2012 (Zado, 2017, p. 2-3).

O MAMM possui área total do espaço de exposição de 448,06 $\mathrm{m}^{2}$, distribuídos em três galerias (Convergência, Retrato-relâmpago e Poliedro), Auditório e Biblioteca especializada (coleções Poliedro, Gilberto e Cosette de Alencar, Cleonice Rainho, Domervilly Nóbrega). O edifício (complexo arquitetônico com acessibilidade adaptada) composto por térreo, primeiro e segundo piso possuem linhas modernistas constituindo um marco na arquitetura local (UFJF, 2014, p. 1). O modo de acesso entre eles se dá por meio de escada e/ou elevador de pessoas.

"Todas as formas ainda se encontram em esboço / Tudo vive em transformação: / Mas o universo marcha / Para a arquitetura perfeita"(Mendes, 1994, p. 410). Eis que a dialética muriliana nos ensina que tudo vive em mudança e, no pensamento contemporâneo - a nova museologia - concebe que as narrativas expositivas como um espaço de construção de significados no qual deverá ocorrer à interatividade com o público, despertando a atenção dos visitantes para as múltiplas funções que a ação museológica se propõe. É, portanto, nesse sentido, que, sob a perspectiva interdisciplinar, se busca cada vez mais o 'diálogo' com os demais setores do MAMM, com vistas à consolidação da prática expositiva. 


\section{'Transformar-se ou não, eis o problema...'}

A qualidade vem sendo tema recorrente em diversos trabalhos nas últimas décadas e ainda continua em pauta como tópico essencial para o desenvolvimento sustentável. As Organizações Nações Unidas (ONU) definiu no âmbito do quarto Objetivo de Desenvolvimento Sustentável (ODS) - 17 são os objetivos para transformar nosso mundo - a questão primordial da educação inclusiva e equitativa e de qualidade, que promova oportunidades de aprendizagem ao longo da vida para todos.

Carvalho, Miguel e Campos (2007) a advertem para o fato de um espaço não formal de educação ser propulsor da qualidade nos serviços de atendimento como condição para atração de reais ou potenciais visitantes (público alvo dos serviços). Desta forma, o percurso da qualidade de serviços, segundo Lourenço e Knop (2011, p. 226) se origina na concepção de que um "[...] serviço será de qualidade se as expectativas dos consumidores forem atendidas ou superadas".

Em suma a qualidade em serviços é a capacidade que uma experiência ou qualquer outro fator tenha para satisfazer uma necessidade, resolver um problema ou fornecer benefícios a alguém (Las Casas, 2017, p. 16). No entanto, não basta a instituição museológica fornecer apenas serviços com excelente qualidade é necessário monitorar as percepções.

Gosling et al. (2016, p. 166) afirmam que "Nos Museus é perceptível que uma visita coerente e satisfatória é formada por diversos fatores, dos quais alguns podem ser controlados pelos gestores, mas outros não". Portanto, o serviço representa sentimento e a comunidade usuária podem ter ou não satisfação diante das expectativas criadas.Prontamente as expectativas dos clientes serão confirmadas (satisfação pessoal) quando as percepções satisfizerem as expectativas.

Portanto, o serviço é julgado pelo cliente como sendo de qualidade pela soma do resultado esperado, pela aparência do prestador e suas habilidades interpessoais (Hoffman \& Bateson, 2006). Esses pesquisadores argumentam que o importante é a 'hora da verdade', com esse momento é possível compreender o espaçamento entre as expectativas e as percep̧̧ões que - sensibilizam estruturalmente - a ancoragem da qualidade. Assim, a definição mais popular da satisfação ou insatisfação da clientela apoia-se numa comparação do desejo e do real desempenho angariado pelo serviço.

Parasuraman, Zeithaml e Berry $(1985,1988)$ relatam que 'qualidade percebida' é uma apreciação global ou uma atitude associada à superioridade do serviço. Além disso, existe uma relação causal entre as dimensões da qualidade e a percepção desempenho dos serviços. Deste modo esses pesquisadores congregam assim cinco 'construtos' - Tangibilidade, Confiabilidade, Receptividade, Garantia e Empatia - que determinam a qualidade em serviços. Essas dimensões são apontadas modelo Servqual e foram detalhadas por Cook, Heath and Thompson (2000) da seguinte forma:

- Tangibilidade (tangibles): facilidades e aparência física das instalações, pessoal e material de comunicação, equipamentos.

- Confiabilidade/Credibilidade (reliability): habilidade em prestar o serviço prometido com precisão e confiança.

- Receptividade (responsiveness): disposição para ajudar o visitante e fornecer um serviço com presteza e rapidez de resposta.

- Garantia (assurance): cortesia e conhecimento do funcionário e sua habilidade em transmitir segurança.

- Empatia (empathy): cuidado em ofertar atenção individualizada a clientela.

Após análise de diversos modelos é essencial que o serviço encontre a ferramenta necessária para medir e avaliar a qualidade de seu serviço e a avaliação Servqual trará justamente o resultado a qual se propõe.

A metodologia Servqual é uma escala de 22 pares de itens que mede percepções e expectativas do cliente perante um rol de assertivas norteadas a cinco dimensões da qualidade do serviço. A abordagem do modelo gap da qualidade, será usada para projetar os dados coletados e classificar a qualidade dos serviços segundo a avaliação de comunidade usuária.

A metodologia compreende uma métrica de ponderação, ou seja, constitui um modelo de avaliação que posiciona itens fundamentais e aderentes a fatores que importam na qualidade dos serviços prestados. Portanto é uma ferramenta de diagnóstico que revela as maiores forças e fraquezas de uma organização na área da qualidade dos serviços.

"Transformar-se ou não, eis o problema"(Mendes, 1994, p. 410) é uma composição muriliana reflete a ideia modificabilidade do cognitivo e seres. Ademais, a imagem institucional se estrutura pela confiabilidade, pelo compromisso de atendimento, pela garantia incondicional que fatalmente conduz à atração de uma comunidade usuária dos serviços de qualidade (Mello, 2010). 


\begin{tabular}{|l|l|c|}
\hline \multicolumn{2}{|c}{ Assertivas métricas na métrica Servqual } & Tang1 \\
\hline \multirow{4}{*}{ Tangibilidade } & Espaço e instalações físicas atraentes & Tang2 \\
\cline { 2 - 3 } & Equipamentos com aparência moderna & Tang3 \\
\cline { 2 - 3 } & Boa aparência dos funcionários & Tang4 \\
\cline { 2 - 3 } & Qualidade do ambiente (limpo, organizado e sinalizado) & Conf5 \\
\hline \multirow{5}{*}{ Confiabilidade } & Interesse em resolver as dúvidas dos visitantes & Conf6 \\
\cline { 2 - 3 } & Funcionários são bem treinados/qualificados & Conf7 \\
\cline { 2 - 3 } & Funcionários mostram disponibilidade & Conf8 \\
\cline { 2 - 3 } & Funcionários têm sincero interesse em sanar dúvidas & Conf9 \\
\cline { 2 - 3 } & A instituição cumpre os horários de atendimento & Rec10 \\
\hline \multirow{5}{*}{ Geceptividade } & Atendimento imediato ao público/comunidade & Rec11 \\
\cline { 2 - 3 } & Informação correta pelos funcionários/monitores & Rec12 \\
\cline { 2 - 3 } & Funcionários sempre dispostos a ajudar o visitante & Rec13 \\
\cline { 2 - 3 } & Funcionários sempre livres para responder dúvidas & Gar14 \\
\hline \multirow{5}{*}{ Empatia } & Funcionários cordiais com o público & Gar15 \\
\cline { 2 - 3 } & Funcionários com postura que inspira confiança & Gar16 \\
\cline { 2 - 3 } & Funcionários bem treinados para atender nas visitas & Emp18 \\
\cline { 2 - 3 } & Funcionários com conhecimento para responder para explicar conteúdos & Emp19 \\
\hline & Horário de funcionamento conveniente para todos & Emp20 \\
\cline { 2 - 3 } & Funcionários ofertam atenção individualizada ao visitante & Emp21 \\
\cline { 2 - 3 } & Tratamento das dúvidas do visitante como prioridade & Emp22 \\
\cline { 2 - 3 } & Funcionários carregam consigo os interesses do público & \\
\cline { 2 - 3 } & Entendimento das necessidades específicas de seu público & \\
& &
\end{tabular}

Quadro 2. Dimensão da qualidade e as assertivas métricas no painel Servqual Fonte: os autores com base em Parasuraman, Zeithaml e Berry $(1985,1988)$.

\section{METODOLOGIA DE PESQUISA}

Esta pesquisa foi realizada na área externa do Museu de Arte [Moderna] Murilo Mendes (MAMM) através de entrevista semiestruturada aplicada no período de 13 de maio a 13 de agosto de 2017, em alternados dias (com exceção das segundas-feiras e demais dias sem funcionamento), entre as $16 \mathrm{~h}$ e as $18 \mathrm{~h}$ - após o visitante sair da edificação do MAMM.

\section{Procedimentos e instrumentos}

Para o desenvolvimento dessa pesquisa optou-se pelo questionário auto preenchido, é que nesse estudo de caso a simplicidade da coleta e análise de dados representa uma vantagem se comparada a outros procedimentos relatados em pesquisas de marketing. A abordagem Servqual envolve a aplicação de questionários e o regaste de dados, assentado os construtos da qualidade como uma base teórica e metodológica.

Assentando que os clientes a cada dia exigem mais qualidade nas organizações prestadoras de serviços, muitos estudos organizacionais reportam que serviços somente podem ser avaliados por quem os utiliza. Daí o empenho das instituições em oferecer benefícios para satisfazer, superar as expectativas, surpreender e encantar seu público.

O método de procedimento Servqual situa 22 pares de afirmações, divididas nos constructos supramencionados entre a Importância (expectativa; desejo) e a Satisfação (desempenho, percepção). A composição das duas seções, uma de 22 itens sobre as expectativas dos clientes e outra também de 22 itens que mede as percepções do cliente, estrutura o resultados das duas seções em forma de comparação diante as 5 opções de respostas psicrométrica Likert. Para limitação das determinantes da qualidade, foi adotada a seguinte notação para as afirmativas:

As questões de 01 a 22 correspondiam às expectativas do cliente e 22 itens espelhos correspondem às percepções do visitante, totalizando 44 itens, além de um espaço aberto as sugestões ou reclamações. A escala do tipo Likert de cinco pontos sinaliza um parâmetro psicrométrico de mensuração, sendo que 1 (um) é representante de uma total discordância do respondente e 5 (cinco) expressa uma total concordância.

O tratamento de dados deu-se através da disposição em tabelas (tabulação MS Excel), análise e interpretação das respostas fornecidas pelos entrevistados. Ao final do processo de coleta de dados, obtiveram-se 144 (96,00\%) questionários aplicados válidos. Corroboram a análise somente os questionários que obtiveram "sim"ao item 'visitei e utilizei o atendimento/serviço do MAMM' No que tange ao roteiro de entrevista, foram introduzidos questões para caracterização do perfil do respondente, tais como: gênero, faixa etária e domicílio. O grupo amostral constituído é não probabilístico e não intencional. 


\begin{tabular}{llrrrr}
\hline Perfil / Gênero declarado & \multicolumn{2}{c}{ Feminino } & \multicolumn{2}{c}{ Masculino } \\
\hline \multirow{3}{*}{ Faixa etária } & $<25$ & 44 & $57,14 \%$ & 47 & $70,15 \%$ \\
& $25-65$ & 22 & $28,57 \%$ & 13 & $19,40 \%$ \\
& $>65$ & 11 & $14,29 \%$ & 7 & $10,45 \%$ \\
\hline \multirow{2}{*}{ Etnia Raça } & Branca & 46 & $59,74 \%$ & 49 & $73,13 \%$ \\
& Pardo/negro & 28 & $36,36 \%$ & 10 & $14,93 \%$ \\
& Outra & 3 & $3,90 \%$ & 8 & $11,94 \%$ \\
\hline \multirow{3}{*}{ Estado civil } & Solteiro & 40 & $51,95 \%$ & 52 & $77,61 \%$ \\
& Casado (juntado) & 29 & $37,66 \%$ & 13 & $19,40 \%$ \\
& Outro & 8 & $10,39 \%$ & 2 & $2,99 \%$ \\
\hline & Total & & n. 77 & n. 67 \\
\hline
\end{tabular}

Tabela 1. Perfil social, $2017(n=144)$

Fonte: dados da pesquisa (2017).

\begin{tabular}{lrrrrrrr}
\hline Dimensões da qualidade & \multicolumn{3}{c}{ Gap Importância (E) } & \multicolumn{3}{c}{ Gap Satisfação (P) } & Total \\
\hline & Feminino & Masculino & Média & Feminino & Masculino & Média & $\mid(\mathrm{P})$ - (E) \\
\hline Tangibilidade & 4,92 & 4,48 & 4,70 & 4,88 & 4,42 & 4,65 & 0,05 \\
Confiabilidade & 4,83 & 4,74 & 4,79 & 4,12 & 4,41 & 4,27 & 0,52 \\
Receptividade & 4,82 & 4,33 & 4,58 & 3,86 & 3,64 & 3,75 & 0,83 \\
Garantia & 4,84 & 4,72 & 4,78 & 3,94 & 4,31 & 4,13 & 0,65 \\
Empatia & 4,29 & 4,38 & 4,34 & 3,78 & 4,02 & 3,90 & 0,44 \\
\hline
\end{tabular}

Tabela 2. Importância e satisfação por dimensão

Fonte: elaborado pelos autores; dados da pesquisa (2017).

\section{APRESENTAÇÃO E DISCUSSÃO DOS RESULTADOS}

Esta seção apresenta e discute algumas perspectivas sobre as informações obtidas, distribuídas em três blocos de análise. Primeiramente mostrar-se as características gerais, sem pretender ser um estudo exaustivo. Na sequência, apresenta-se uma análise básica com a métrica Servqual. E no último bloco, resgatam-se opiniões dos entrevistados acerca da experiência com o serviço, enunciando um painel qualitativo a abordagem.

\section{Características gerais}

Do total de 144 respondentes, quanto ao gênero, 77(53,47\%) se declararam feminino e 67(46,53\%) masculino.

Quanto à faixa etária, 91 (63,19\%) dos entrevistados estavam entre 18 e 25 anos e os demais $53(36,81 \%)$ dos abordados, mais de 25 anos, conforme apresenta a Tabela 1 . No que se refere ao estado civil e etnia, a maioria dos respondentes se declara branco/branca $95(65,97 \%)$ e solteiro/solteira $92(63,89 \%)$.

\section{Análise Servqual - Importância \& Satisfação}

No que tange à expectativa (E) o 'espaço e instalações físicas atraentes', 141 (97,92\%) deram pontuação máxima. Com relação à satisfação $(\mathrm{P})$, o item obteve 136 respondentes $(92,86 \%)$ que atribuíram valor máximo na percepção da atratividade do espaço e das instalações físicas (aspecto tangível).

Analisando a média das cinco determinantes da qualidade em serviços, verificamos que a Importância/Expectativa (E) obteve uma pontuação variante entre 4,34 e 4,79. E ao considerar a média das determinantes sobre o cenário da Satisfação/Percepção $(\mathrm{P})$, verifica-se pouca variação escalar, ou seja, o desempenho auferiu avaliação média entre 3,75 e 4,27 em uma escala de cinco pontos. Para o cálculo das médias, as pontuações (de 1 a 5 ) de cada assertiva são somadas em suas relativas dimensões e depois divididas pelo número total de respondentes - tanto para a importância (E), quanto para a satisfação $(\mathrm{P})$.

A Tabela 2 apresenta a média da pontuação (em uma escala de 1 a 5) recebida perante os indicadores da qualidade de serviço, agrupados por dimensão:

Pode-se deduzir que o item com o menor gap na opinião dos respondentes foi relacionado os aspectos tangíveis $(4,65-4,70=|0,05|)$. Aplicando-se o mesmo nexo às outras determinantes, observa-se que a maior lacuna está no construto relativo à Receptividade $(|0,83|)$, entendida como "sensibilidade - disposição para ajudar os clientes e prestar um serviço rápido [...]" (Las Casas, 2017, p. 215) que o prestador de serviços proporciona a sua clientela.

A Receptividade obteve nessa pesquisa os menores índices de satisfação $(3,75)$ e em ambos os gêneros (Fem. 3,86; Masc.3,64) esta condição é destacada; a Figura 2 ilustra as proporções em termos dos gaps, assinando assim que quanto maior a lacuna maior é o distanciamento de um status de alta performance (excelência). 


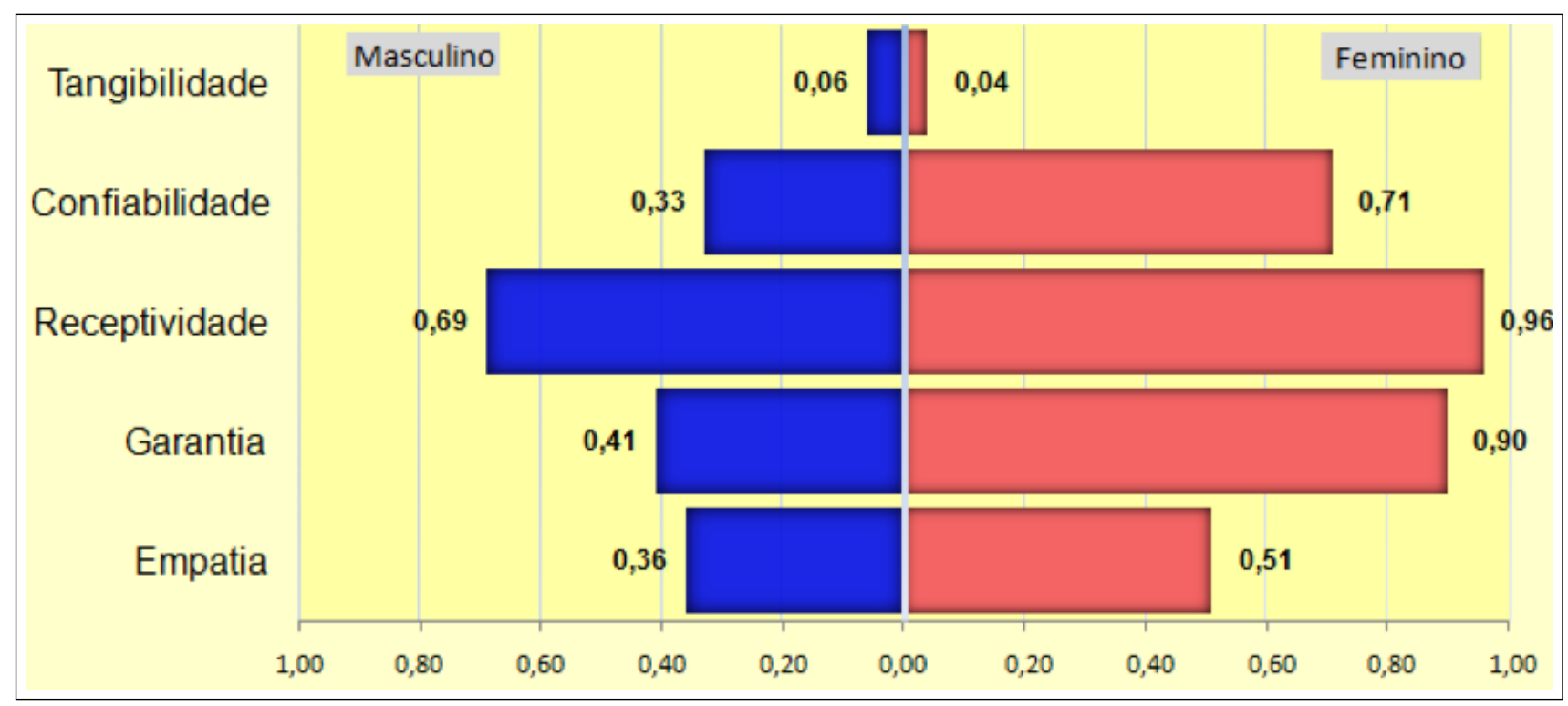

Figura 2. Gráfico dos gaps por dimensão da qualidade Fonte: dados da pesquisa (2017)

Nota-se que o gap em Tangibilidade, Empatia e Confiabilidade apresentam menor lacuna. Berry (1996) esclarece que a confiabilidade é a dimensão do 'resultado' de um serviço; as demais dimensões seriam julgadas após o processo de desenvolvimento de serviços, dessa forma, entende-se que a dimensão confiabilidade é de culminante significado para as melhores práticas em gestão local e para a imagem organizacional.

\section{Registro e regaste de depoimentos}

Na composição desta pesquisa, incluiu-se um espaço para registro de depoimentos/opiniões sobre o museu (MAMM. A seção aberto a free elicitation recebeu 28 (19,44\%). Em geral observa-se que as sensações de satisfação ou insatisfação remetem a ambiência, não obstante as queixas e experiências focam a questão do acervo, tal como os registros a seguir:

O museu é educativo e tem informações. É um local com exposições temporárias. Um local pequeno, mas adequado. Um bonito prédio com boa localização, bem central. Todas as vezes que visitei o MAMM tive experiências ótimas. Se a pessoa se interessa por arte contemporânea, não deixe de visitar (Entrevistad@ A).

O Museu é pequeno se comparado à grandes museus de Rio e São Paulo porém seu acervo é extremamente valioso, vale a pena a visita. A equipe que acompanha [as visitas] é muito atenciosa e complementa com informações sobre as obras e os artistas. O espaço possui um acervo de obras de arte moderna muito expressivo. Sempre podemos encontrar alguma exposição montada, várias vezes no ano (Entrevistad@ B).

No que se refere à percepção social sobre o poeta Murilo Mendes nove respondentes $(32,14 \%)$ utilizaram o espaço para reportar que o espaço museológico desperta o interesse para a literatura, constituindo-se o museu um pilar de expressão linguística, letramento e inclusão social.

Recomendo outros visitantes a conhecer a sala onde ficam as exposições com objetos, quadros do acervo pessoal do Murilo Mendes. É bem bacana, chega a ser interessante, mas nada muito imperdível. Senti falta de um maior acompanhamento por parte dos funcionários. A recepção é muito boa, mas faltou interação (Entrevistad@ C).

O MAMM na opinião de um entrevistado possibilita "acessibilidade e sem barreiras físicas, mentais, sensoriais, intelectuais ou sociais [...] para contemplar a arte contemporânea". Esse olhar sobre o museu parece, assim, adentrar no painel da Receptividade, envolvendo itens de boa vontade, atendimento com presteza e disposição para tirar dúvidas, como frisa o entrevista@ "D":

Um dos principais museus da cidade, infelizmente não possui muitas obras. O museu conta com um acervo modesto, mas interessante, a infraestrutura do prédio é muito boa! Arejado, bem iluminado, e acessível. Mas o atendimento deixou a desejar, afinal o pessoal estava aflito para o fechamento e não atendeu tão bem, tendo má vontade em prestar informação sobre a biblioteca do espaço (Entrevistad@ D).

No que tange às apreciações sobre - confiabilidade, garantia e receptividade - surgiram em poucos trechos e não 
adentram em pontos cruciais de análise; todavia a questão de ações sensoriais é destacada e apontada como desejo para que gestores da instituição alavanquem o processo de desenvolvimento de serviços.

\section{CONSIDERAÇÕES FINAIS}

Este estudo foi realizado com o objetivo de investigar a qualidade dos serviços prestados pelo Museu de Arte Murilo Mendes (MAMM) a partir do olhar da comunidade usuária e, tal abordagem carga mais um contexto mais auspicioso pois direcionar a avaliação da percepções e expectativas a quem realmente utiliza os serviços.

O objetivo desta pesquisa foi avaliar a qualidade dos serviços prestados em um espaço não formal de educação, considerando as percepções e as expectativas sobre os serviços prestados pelo MAMM. Optando-se por simplificar as múltiplas facetas circunjacente a avaliação de serviços adotando-se a abordagem teórico-metodológica Servqual - uma métrica para avaliação da qualidade em serviços amplamente validada por diversas pesquisas.

A fundamentação teórico-metodológica do presente diagnóstico reporta estreita relação com administração e processo de desenvolvimento de serviços, satisfação dos clientes, qualidade e sua avaliação utilizando os preceitos da métrica Servqual. No que tange ao método Servqual, com as devidas adaptações, sua aplicação nesta pesquisa revelou-se como abordagem viável para se avaliar a qualidade a partir das percepções e expectativas dos visitantes de espaços museais.

E com olhar dos visitantes averigua-se a arquitetura perfeita dos serviços. O método escolhido para estudo apresenta certas limitações, a saber: a faixa etária estabelecida (18 ou mais anos), os distintos serviços (setores biblioteca, hemeroteca e informação; museológica; difusão cultural e a educativa), o horário e o período de sondagem. Diante esse painel, outras carências podem ser destacadas: a) Necessidade de efetivação do Programa de Segurança, conforme prevê a Lei $\mathrm{n}^{\circ}$ 11.904; b) Necessidade de revisão do sistema de segurança, considerando a obsolescência de alguns equipamentos e dispositivos de segurança como: sensores de fumaça, detectores de presença e câmeras; c) Necessidade de revisão da sinalização interna, em especial no que se refere às rotas de escape e evacuação do prédio em hipótese de sinistros; e d) Necessidade de implantar sinalização externa, alusiva ao MAMM, no perímetro urbano da cidade.

A dialética de Murilo Mendes nos ensina que tudo vive em 'transformação'. Essa diretriz deve norte a construção do Novo Plano Museológico. A receptividade vista como capacidade de respostas da instituição para solucionar dúvidas e anseios de seus visitantes, é um aspecto relevante que sobressaiu negativamente $(-0,83)$ entre as demais determinantes da qualidade em serviços. A despeito dessa resultante ficou evidenciado que os respondentes consideram que a ambiência poderia desencadear melhor envoltura emocional com informações e os sentidos, que num da filosofia schopenhaueriana, remete a ética da compaixão, inerente ao aspecto de visitação. No geral, os resultados mostram as possibilidades de aprimoramento das dimensões da qualidade Servqual, e que podem ser mais bem exploradas. Como continuidade dos trabalhos, sugere-se avaliar o nível efetivo de satisfação dos clientes com apoio da métrica Servqual ou alguma de suas variações (Tourqual, Histoqual). Portanto, identificar o tipo de ação com maior impacto na percepção dos clientes poderá surtir para um melhor desempenho institucional. Entende-se que os gaps da qualidade em serviços apresentam oportunidades de estudos.

Assim, entendemos que o resultado palpável de convergências nesse tipo de diagnostico visa a possibilidade de formular projetos de investigação interdisciplinares em que a gestão de serviços opera como vetor da cultura informacional nas práticas sociais observados na obra de Bourdieu em uma verticalização para campo da informação no intuito de enlaçar as múltiplas evidências das práticas sociais (Marteleto, 2017).

A partir das conclusões expostas, algumas opções para pesquisas vindouras possam associar o método Servqual a outras abordagens metodológicas qualitativas, algo que começou a ser desenhado neste estudo, contudo pouco desenvolvido diante a prática metodológica adotada. Ademais, o espaço museológico também adentra nos ODS do milênio e assim dever ser um território premiado e transformado pelo ensejo da qualidade em serviços. 


\section{REFERÊNCIAS}

Berry, L. L. (1996). Serviços de satisfação máxima: guia prático de ação. Campus.

Bourdieu, P., \& Darbel, A. (2007). O amor pela arte: os museus de arte na Europa e seu público (2a. ed.). Zouk.

Brasil. Ministério da Cultura. (2015). Museu de Arte Murilo Mendes. Museusbr. Recuperado em 22 nov. 2017, de http:// museus.cultura.gov.br/agente/11464/

Carvalho, S. M. S. d., Miguel, M. C., \& Campos, A. C. B. (2007, 6). Aproveite a sua passagem e viaje pelo mundo da leitura: uma análise das Bibliotecas Transcol de Vila Velha por meio da ferramenta Servqual. RDBCI: Revista Digital de Biblioteconomia e Ciência da Informação, 16(3), 408-426. Recuperado em 15 dez. 2018, de https://periodicos.sbu.unicamp.br/ojs/index.php/rdbci/ article/view/8651239 doi: 10.20396/rdbci.v16i3.8651239

Cook, C., Heath, F., \& Thompson, R. L. (2000, 12). A meta-analysis of response rates in Web-or Internet-based surveys. Educational and Psychological Measurement, 60(6), 821-836.

Cunha, M. (2018, 11). Um museu em chamas: o caso do Museu Nacional do Rio de Janeiro. Revista IberoAmericana de Ciência da Informação, 12(1), 1-3. doi: 10.26512/rici.v12.n1.2019.19354

Dlačić, J. e. a. (2014, 11). Exploring perceived service quality, perceived value, and repurchase intention in higher education using structural equation modelling. Total Quality Management \& Business Excellence, 25(1-2), 141-157. doi: $10.1080 / 14783363.2013 .824713$

Gaspar, A. (1993). Museus e centros de ciências: conceituação e proposta de um referencial teórico (Tese de doutorado em Educação, Faculdade de Educação, USP, São Paulo). Recuperado em 30 nov. 2016, de http://www.casadaciencia .ufrj.br/Publicacoes/Dissertacoes/gaspar-tese.PDF

Gomes, I., \& Cazelli, S. (2016, 3). Formação de Mediadores em Museus de Ciência: saberes e práticas. Ens. Pesqui. Educ. Ciênc., 18, 23-46. Recuperado em 18 fev. 2017, de http://www.scielo.br/scielo.php?pid=S1983 $-21172016005001102 \&$ script $=$ sci_abstract\&tlng $=$ pt doi: 10.1590/1983-21172016180102

Gosling, M. S., Silva, J. A., Mendes, J., Coelho, M. F., \& Meira, K. C. O. (2016). Avaliando a Qualidade de Serviços em Museu: Validação e Teste de Escala. Rosa dos Ventos Turismo e Hospitalidade, 8(2), 162-176.

Hallal, D. R., \& Muller, D. (2016, 12). Educação Patrimonial no Museu Municipal Parque da Baronesa como possibilidade de Turismo Cidadão. RELACult Revista Latino-Americana de Estudos em Cultura e Sociedade, 2(1-2), 208-224. Recuperado em 18 dez. 2018, de http://periodicos.claec.org/index.php/relacult/article/ view/305 doi: 10.1080/14783363.2013.824713

Hoffman, K. D., \& Bateson, J. E. G. (2006). Principios de marketing de serviços: Conceitos, Estratégias e Casos. Pioneira Thomson Learning.

Instituto Brasileiro de Museus (IBRAM). (2018). O Registro de Museus. Ibram/MinC. Recuperado em 11 abr. 2018, de http://www.museus.gov.br/tag/registro-de-museus /

Las Casas, A. L. (2017). Qualidade total em serviços: conceitos, exercícios, casos práticos (6a. ed.). Atlas.

Lourenço, C. D. D. S., \& Knop, M. F. T. (2011, 7). Education in Business Administration High and Services Quality
Perception: a SERVQUAL scale application. Review of Business Management, 13(39), 219-233. Recuperado em 17 nov. 2017, de https://rbgn.fecap.br/RBGN/article/view/ $854 / 752$

Marteleto, R. M. (2017). A cultura, o conhecimento e ainformação na obra de pierre bourdieu. In R. M. Marteleto \& R. M. E. Pimenta (Eds.), Pierre bourdieu e a produção social da cultura, do conhecimento e da informação. Rio de Janeiro, RJ: Garamond.

Mello, C. H. P. e. a. (2010). Gestão do processo de desenvolvimento de serviços. Atlas.

Mendes, M. (1994). Poesia completa e prosa. Nova Aguilar.

Miguel, M. C. (2017, 7). Múltiplos olhares em prol da qualidade de serviços biblioteconômicos. Revista $A C B$, 22 (2 Especial), 192-207. Recuperado em 27 mai. 2018, de https:// revista.acbsc.org.br/racb/article/view/1312

Museu de Arte Murilo Mendes (MAMM). Universidade Federal de Juiz de Fora. (2015). Plano Museológico: 20152018. UFJF, Pró-Reitoria de Cultura. Recuperado em 15 jan. 2018, de http://www.museudeartemurilomendes.com.br/r/ wp-content/uploads/2017/10/Plano_09102017.pdf

Parasuraman, A., Zeithaml, V. A., \& Berry, L. L. (1985). A conceptual model of service quality and its implications for future research. Journal of Marketing, 49(4), 41-50.

Parasuraman, A., Zeithaml, V. A., \& Berry, L. L. (1988). Servqual: a multiple-item scale for measuring consumer perceptions of service quality. Journal of Retailing, 64, 12-40.

Rebello, M. A. d. F. R. (2004, 12). Avaliação da qualidade dos produtos/serviços de informação: uma experiência da biblioteca do Hospital Universitário da Universidade de São Paulo. RDBCI: Revista Digital de Biblioteconomia e Ciência da Informação, 2(2), 80-100. doi: 10.20396/rdbci.v2i1.2075

Soares, L. M. F., \& Sousa, C. V. e. $(2015,6)$. Percepção da qualidade de serviços nas bibliotecas da Universidade Federal de Ouro Preto na perspectiva do usuário. Perspectivas em Ciência da Informação, 20(2), 79-99. Recuperado em 18 fev. 2017, de http://portaldeperiodicos.eci.ufmg.br/index.php/ $\mathrm{pci} /$ article/view/2050

Universidade Federal de Juiz de Fora (UFJF). (2014). Carta de Serviços ao Cidadão: Museu de Arte Murilo Mendes. UFJF, Pró-Reitoria de Cultura. Recuperado de http://www.ufjf.br/servicos/2014/01/27/museu-de-arte -murilo-mendes/

Universidade Federal de Juiz de Fora (UFJF). (2018, 6). Mamm é a primeira instituição da região a receber selo "Museu Registrado". Recuperado em 20 jul. 2018, de https:// www2.ufjf.br/noticias/2018/06/20/mamm-e-a-primeira -instituicao-da-regiao-a-receber-selo-museu-registrado/

Zado, R. C. d. O. M. (2017, 12). Museu de Arte Murilo Mendes: aquisições contemporâneas. In Universidade de Brasília: Encontro do Grupo MODOS: histórias da arte em museus (v. 4, p. 2-3). Grupo MODOS. Recuperado em 15 jan. 2018, de http://conferencias.unb.br/public/conferences/ $37 /$ schedConfs/63/program-pt_BR.pdf

Como citar este artigo (APA):

Miguel, M. C., Campos, A. C. B. \& Carvalho, S. M. S. de (2018). Museu de arte moderna: a questão da qualidade de serviços. AtoZ: novas práticas em informação e conhecimento, 7(1), 21 - 30. Recuperado de: http://dx.doi.org/10.5380/atoz.v7i1.65350 